\title{
On Your Ranch, Are People a Strength or Headache?
}

\section{By Bernie Erven and Tommy Gilmore}

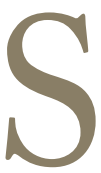
uccessful ranch management requires mastering four different types of management: production management, financial management, marketing management, and human resource (HR) management. Ranchers are most likely to focus on, and therefore excel in, production management where the emphasis is on their cattle and their land. But ranchers must also consider the aspects of financial, marketing, and HR management. Success with production, financial, and marketing management generally leads to business growth, more employees, and the increasing importance of employees to be competent, to be motivated, and to be rewarded fairly. This then requires more emphasis on HR management, which in turn can enhance performance and effectiveness in the other three areas of management.

Today, some ranchers can say with confidence that their people skills have become as important as their cattle skills. The good news is that any rancher can decide to make his or her workforce a strength rather than a headache. More good news for ranchers is that success with employees depends primarily on relationships rather than on mysterious and complicated recipes that must be followed. This means that two ranchers can be highly successful with employees even though they may build relationships in quite different ways.

No rancher likes having a reputation as a "poor boss." Yet many suffer from reputations that have grown out of their history of treating employees badly. Why do these ranchers consider people a headache? Because they have been unwilling or unable to learn and change! There is an important side benefit of becoming known as a "great boss." Good relations with employees make ranching more enjoyable. When the headaches related to the employees are mostly gone, a rancher will have a vast majority of days when people are thought of as assets to the ranch rather than as part of what is broken on the ranch.

The HR guidelines highlighted here are intended for a wide array of ranch managers. The basics of HR management extend across ranches of all sizes. Ranch personnel that use sound HR skill sets, whether on the largest ranches or on the smallest, make the same kinds of choices and depend on the same principles to guide these choices. People matter on all ranches. No ranch succeeds while its employees and managers are failing. This fact assures that those ranch managers who treat HR management as unimportant make HR choices that cause ranch failure, regardless of the numbers of cowboys, cows, or acres.

No rancher can thrive as a leader without making good choices that grow out of his or her commitment to employees and to a goal of success. Ranchers must continuously remind themselves that they are as good at handling HR issues as they choose to be. Our goal is to help ranchers build and improve upon their people management skills in order to make better choices that will lead to having a workforce that is the strength of their operations, not a headache.

\section{Five Key HR Tasks for Ranch Managers}

Five key HR tasks that undergird the choice to make HR management an important part of a ranching operation are these:

1. Create a vision

2. Develop goals

3. Craft an organizational structure

4. Put the "right" HR practices in place

5. Equip managers to lead

Ranch managers can think of these five tasks as a starting point in making better choices. Better choices will lead to better relationships with employees, and the ranch manager will build a reputation of being a "great boss." In turn, employees will think of the ranch as a good place to work.

\section{Task 1: Create a Vision of HR Success}

An HR vision statement is a broad statement that guides action and helps measure progress. Any rancher can stumble along without a clear vision of what he wants to accomplish with his HR management. No two ranches have the same vision. An example of a vision statement to guide HR choices is this: "The best cowboys work on our ranch." This vision suggests that who is hired to work on the ranch and who stays are considered important. It also suggests that training cowboys to be as good as possible is important. One can easily see a variety of ways that this straightforward, 
A. "Me" Structure

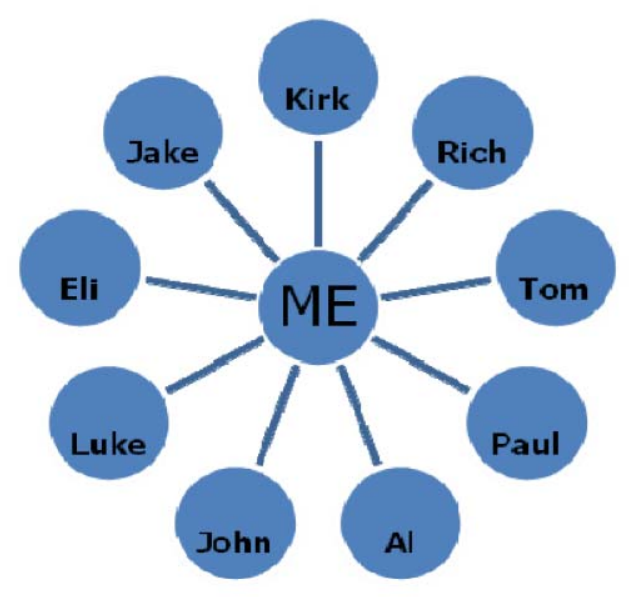

B. Vertical Structure

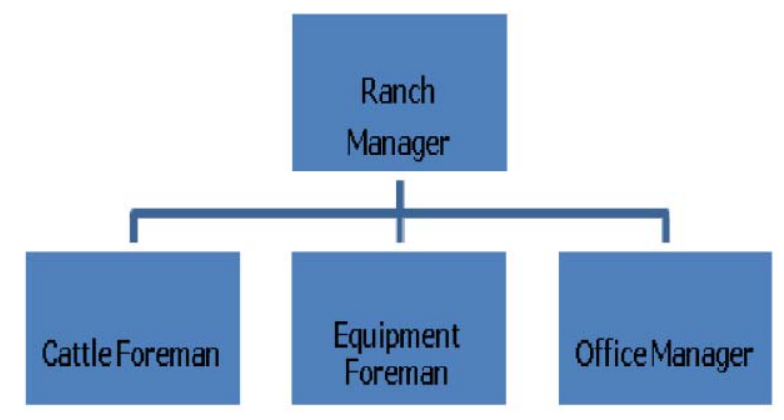

Smaller

Time

Larger

Ranch Growth

Figure 1. Organizational structure. Smaller ranches usually start out with a "me" organizational structure, but over time, and as the ranch grows, the organization of the ranch will evolve into a more vertical structure.

one-sentence HR vision statement can guide actions affecting employees and the ranch in general.

Consider the following question: "Would you prefer to hire four superb cowboys back-to-back who each stay 5 years, or would you rather hire one 'just okay' cowboy who stays 20 years?" Choosing one who is likely to stay 20 years rather than hiring four superb ones over 20 years illustrates very different visions driving hiring. Some ranchers may think that they have to take whomever they can get to work, regardless of their abilities. This suggests quite a different HR vision than "The best cowboys work on our ranch." The good news is that each ranch manager has a choice to make about vision. An HR vision that is good for the overall success of the ranch is a choice, just as a vision of "hiring whomever we can get or whoever drives down the driveway" is a choice.

Take away message: Having an HR vision is under the control of each rancher, and having a vision of what each ranch manager wants to accomplish will help him or her succeed because it will guide decisions and actions.

\section{Task 2: Develop HR Strategic Goals}

The importance of production, marketing, and financial goals has long been known by progressive ranchers. Human resource goals can help just as much. Like the strategic and operational goals for production, marketing, and finance, HR goals are most helpful when they are SMART: Specific, Measurable, Attainable, Rewarding, and Timed.

Here is an example of an HR goal that meets these five criteria: decrease annual turnover of employees from 33\% to
$10 \%$ by the end of 2012. Imagine a ranch struggling with a third of its employees being new every year. Management time spent hiring, training, and dealing with problem employees is substantial. The sample goal targets a measurable decrease to $10 \%$ in two years. This goal presents a specific challenge that is possible to attain within a given time period. The result will be a rewarding decrease in headaches with employees, improved employee morale, and a better reputation as a workplace.

Take away message: Ranchers with specific HR goals have better results than those who have only general or vague goals.

\section{Task 3: Craft an Organizational Structure}

Every business has an organizational structure. This structure determines who is an employee's supervisor, whom if anybody an employee supervises, and how one employee's level of responsibility in a ranch compares to another's. For example, the comparative roles of head cowboy versus office manager differ. The organizational structure also lays out a chain of command and helps sort out the formal communication channels from those that are informal. A ranch's organizational structure may be confused or orderly, formal or informal, well understood or not understood at all, and helpful or hurtful to the functioning of the ranch.

To illustrate two sharply contrasting structures, one ranch has a vertical structure while another has a "me" structure (Fig. 1). With a vertical structure, for example, cowboys report to a head cowboy, the head cowboy reports to the ranch foreman, and the ranch foreman reports to the ranch owner/operator. This is a vertical structure because everyone 
but the owner/operator has someone above him or her to whom to report.

With a "me" approach, there is no vertical structure. Instead, everyone who is working on the ranch reports to the same person-for example, the owner/operator of the ranch. The structure is circular in nature, with the numberone person being at the center of everything that happens. A "me" approach is common in small ranches, but as a ranch grows and adds employees, the top person's continued success is likely to require some form of vertical structure in which the "me" person delegates some responsibilities that are no longer a good use of his or her time. The ranch's success has a higher priority than the "me" person's ability to maintain control of every detail.

Take away message: A ranch's organizational structure is either an asset or a liability to continued success; it is never an unimportant detail. Again, choices made by the ranch manager are important because of how those choices affect relationships with employees.

\section{Task 4: Put the "Right" HR Practices in Place}

Once decisions about vision, strategic goals, and organizational structure have been made, the challenge of putting the "right" HR practices in place remains. The overall challenge of HR management can be broken down into many step-by-step processes. The five most important categories of $\mathrm{HR}$ practices are these:

1. HR planning

2. Hiring

3. Training

4. Building relationships with employees

5. Operating within the Federal and state labor laws that apply to ranch employers and employees

Examples of these include the following: 1) the process by which a position for a new cowboy is filled; 2) the way job interviews are conducted and by whom; 3 ) the responsibilities given to inexperienced cowboys versus those given to experienced cowboys; 4) disciplinary action for mistreating an animal on the ranch; and 5) the training program an office worker must complete before being eligible for promotion to office manager.

Developing the "right" practices depends on vision, strategy, structure, and other details that make ranches and ranchers different from each other. No set of practices in each category is right for all ranches. The influence they have on the success of the ranch is what makes these five groups of practices important. Additional categories of practices that are generally less important than the five listed include the following examples: orientation of new employees, motivation, conflict management, discipline, feedback on performance, and pay packages. The five main categories listed above should receive attention before time is spent on less important practices.

Take away message: The right practices must be chosen and put in place. A ranch manger should first devote attention to HR planning, hiring, training, building relationships with employees, and applicable labor laws. Then attention can be devoted to choices that must be made about other less important practices. Any one practice or procedure can be critical to HR success or failure. No matter which combination of practices a ranch manager chooses, the practices must be handled well, and employees need to understand the reasoning behind the choices the manager has made. There are no unimportant HR practices.

\section{Task 5: Equip Managers to Lead}

A good ranch manager is always on the lookout for a current employee who shows potential for more responsibility and promotion to a higher-level position. An employee ready for promotion means that the ranch manager has done several things right-he or she has hired a person with potential, then has trained the person to do his or her job well, and has watched the employee's performance with a sharp eye while coaching effectively. However, a false sense of security may accompany this success story. The ranch manager's enthusiasm for a high-performance employee can easily lead to a critical oversight.

Outstanding work performance and ranch experience at one level does not adequately prepare an employee to succeed at the next level. For example, the best cowboy on the ranch needs training for the leadership responsibilities that come with being the head cowboy. A promotable employee is likely to need additional training and careful assistance during the first few weeks in the more demanding position. In turn, without additional training, the head cowboy who has performed well and has shown readiness for promotion is not yet ready to be assistant ranch manager. Significant harm can be done to an employee's self-confidence and reputation on the ranch by assigning responsibilities in a new position without also providing needed training and close supervision.

Take away message: Outstanding success at one level in the ranch does not by itself prepare a person to succeed at the next level. Unless properly trained and prepared, promotion can ruin a good employee and can leave him or her longing for the success enjoyed in the old position. It is the employer's duty to properly equip new managers to lead.

\section{An Important "Why" Question}

Master HR managers make their success look easy. People like working at their ranches. These ranchers consider employees to be a valuable ranch asset. Productivity and morale at their ranches are high. Turnover is low. They like and enjoy their employees. They rarely complain about headaches with problem employees. Why? This is an important question. Answering it provides more insight about HR management and more reasons for ranchers to be optimistic about the opportunities for employees to be a strength rather than a headache.

The following three reminders are simple, yet powerful, not only because they help us answer the why question but 
also because they show how to make HR management a strength on a ranch operation:

1. Genuinely care about your employees as people.

2. Make clear your trust of employees and your fairness in working with them.

3. Praise hard-earned progress.

Genuinely caring about employees as people means taking an active and honest interest in their lives. Caring is an active process that depends more on what the manager does than on what he or she thinks. This depends more on what a manager says to employees than on what employees say to each other. It is more important to communicate interest in employees as people than to assume that they know the ranch manager cares. Each of the following actions expresses that a ranch manager cares about employees: 1) attending birthday parties, weddings, and family celebrations when invited; 2) recognizing difficult periods in an employee's life such as a death, a serious family illness, or a divorce; and 3) encouraging an employee to attend conferences and short courses to improve his or her skills. It is important to expect the ranch's very best employees to appreciate your interest just as much or more than average employees.

Being viewed by their employees as trustful and fair is also very important for a ranch manager. Trust and fairness help make the ranch manager predictable. These characteristics also increase acceptance of the manager's policies, procedures, and rules because employees expect that the manager has good reasons for the requests or demands made. An irony here is that if a ranch manager is willing to show trust in their employees, the manager will earn even more trust from them.

Praise of hard-earned progress shows the ranch manager's appreciation for extra effort. This extra effort is hugely different from average performance or just getting by in a job. A simple thank you or compliment for a job well done may be remembered for years by an employee. Avoid the trap of thinking that an employee already knows that the manager is pleased with the job the employee is doing. The employee may know it, but hearing it from a respected employer or supervisor adds much meaning.

Take away message: The important things that a ranch manager does with ranch employees may seem obvious, simple, and hardly worth talking about. However, ranch managers must recognize that employees are human beings, not just human resources serving the business.

\section{Summary}

A ranch manager has the opportunity to make a basic choice about employees, to choose a future, and to enjoy a high degree of success. Outstanding HR management is a realistic goal for virtually all managers. The size of the ranch, the number of employees, or the location of the ranch does not determine success or how important employees are to the ranch. Choices made about how to treat people, rather than natural people skills, are the key. A magical recipe or single recipe that fits all managers need not be of concern. Successful HR managers find ways to build good relationships with their employees. These managers work hard to understand some basic practices, and then they use them in a consistent and committed way. A successful ranch manager should aspire to create a reputation for the ranch as a good place to work. Employees also want to work for the ranch that has a good reputation for managing people. Successful ranch managers and ranch employees want to work for a ranch where people are considered to be strengths of the ranch and not headaches.

Authors are Professor Emeritus, Dept of Agriculture, Environmental, and Development Economics, Obio State University, Columbus, OH 43210, USA (Erven); and Graduate Student, King Ranch Institute for Ranch Management, Texas AEฐM University-Kingsville, Kingsville, TX 78363-8202, USA, Tommy.Gilmore@students.tamuk.edu (Gilmore). 